\title{
The Action of Anticholinergic Drugs on the Oxidation of Indole Activated by Acetylcholine Chloride
}

In a previous paper it was shown that acetylcholine chloride (Ach) activates the oxidation of indole to indigo ${ }^{1}$. It has been assumed that Ach acts in a similar way as does peroxidase, namely that it transfers the oxygen from the oxygen-donor (sodium perborate) to the substrate (indole). This is not a true catalytic action, as Ach hydrolyses during the reaction. Nevertheless, when small concentrations of Ach are used, the laws of enzyme kinetics may be applied to this reaction. Some other cholinomimetic agents possess a similar activating activity ${ }^{2}$.

The purpose of this work is to establish whether anticholinergic drugs, which block the pharmacological action of Ach, are capable of inhibiting also the activating action of Ach.

The course of the reaction of the oxidation of indole may be followed by fluorescence measurements, as the intermediate compounds indoxyl and indigo white show an intense blue-green fluorescence, when irradiated by UV-radiation of $3000-4000 \AA^{3}$. Fluorescence measurements were carried out by a fluorometer described earlier ${ }^{4}$. A selen photoelement served as the receptor of radiation, and the photocurrent was measured by a mirror galvanometer (sensitivity $1 \times 10^{-8} \mathrm{Amp} / \mathrm{mm}$ ).

The total volume of the reaction mixture was always $50 \mathrm{ml}$. It contained $0.2 \%$ of sodium perborate, $0.02 \%$ of indole dissolved in isopropyl alcohol, $20 \%$ of acetone and the anticholinergic drug. After determining the fluorescence intensity of this blank, Ach was added $\left(2.2 \times 10^{-4} M\right.$ in the reaction mixture). The solution was well mixed and measurements of the fluorescence intensity

Concentration of the anticholinergic drugs required to reduce by half the maximum reaction velocity of the oxidation of indole, activated by $2.2 \times 10^{-4} \mathrm{M}$ of acetylcholine chloride

\begin{tabular}{ll}
\hline Anticholinergic drug & $\mathrm{C}_{1 / 2}$ \\
\hline Atropine sulfate & $3.6 \times 10^{-4} \mathrm{M}$ \\
Aminopentamide hydrogen sulfate & $3.3 \times 10^{-4} \mathrm{M}$ \\
Procyclidine $\mathrm{HCl}$ & $4.5 \times 10^{-4} \mathrm{M}$ \\
Dicyclomine HCl & $7.5 \times 10^{-4} \mathrm{M}$ \\
Adiphenine HCl & $1.14 \times 10^{-3} \mathrm{M}$ \\
Piperidolate HCl & $1.30 \times 10^{-3} \mathrm{M}$ \\
Tricyclamol Cl & $1.48 \times 10^{-2} \mathrm{M}$ \\
Hexocyclium methylsulfate & $1.74 \times 10^{-2} \mathrm{M}$ \\
Diphemanil methylsulfate & $>3.00 \times 10^{-2} \mathrm{M}$ \\
\hline
\end{tabular}

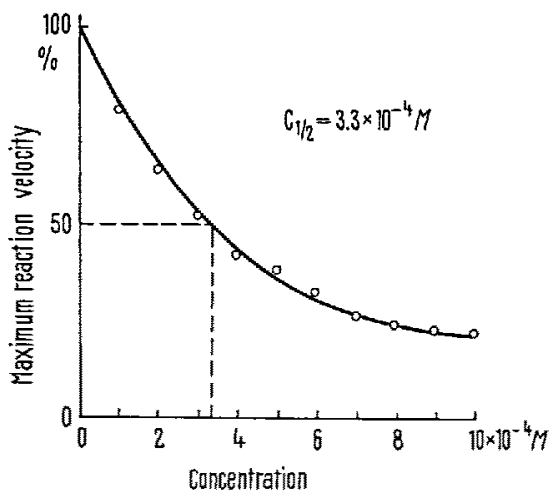

Maximum reaction velocity as a function of aminopentamide hydrogen sulfate concentration. Activator: acetylcholine chloride, $2.2 \times 10^{-4} \mathrm{M}$. started $30 \mathrm{sec}$ later. Readings were taken every minute for several minutes and the results recorded as fluorescence intensity vs, time plots. Maximum reaction velocity was obtained by drawing a tangent at the steepest part of the curves thus obtained and by determining the ordinate of this tangent for the reaction time of $2 \mathrm{~min}$.

The action of the following anticholinergic drugs was investigated: atropine sulfate (Medika), aminopentamide hydrogen sulfate ('Centrine', Bristol Laboratories), procyclidine HCl ('Kemadrin', Burroughs Wellcome), adiphenine $\mathrm{HCl}$ ('Trasentine', Ciba), piperidolate $\mathrm{HCl}$ ('Dactil' Lakeside Laboratories), dicyclomine $\mathrm{HCl}$ ('Wyovin', Wyeth Intern.), tricyclamol $\mathrm{Cl}$ ('Lergine', Burroughs Wellcome), hexocyclium methylsulfate ('Tral', Abbott Laboratories) and diphemanyl methylsulfate ('Prantal', Schering Corp.). All these drugs were dissolved in water, except dicyclomine $\mathrm{HCl}$, which was dissolved in dilute ethyl alcohol.

Addition of the anticholinergic drugs to the reaction mixture (before adding Ach) caused a decrease in reaction velocity. By increasing the concentration of these drugs maximum reaction velocity decreases in accordance with the STERN-Volmer hyperbolic law of inhibition ${ }^{5}$. The values of maximum reaction velocity in presence of the inhibitor are given as percentage of the maximum reaction velocity without inhibitor $(\mathrm{v}=100)$. Plotting these values vs. inhibitor concentration the curves of inhibition are obtained. For example, the curve of inhibition for aminopentamide hydrogen sulfate is presented in the Figure. The concentration $\mathrm{C}_{1 / 2}$ of the inhibitor required to reduce the maximum reaction velocity of the uninhibited reaction by half is used as an index of inhibitory potency. The experimentally obtained results for $C_{3 / 2}$ are given in the Table.

From the present experiments it is evident that anticholinergic drugs inhibit the oxydation of indole. In the absence of activator, this reaction is extremely slow. Therefore one may conclude that in fact the anticholinergic drugs inhibit the activating action of Ach. Our results indicate that there is a certain parallelism between the pharmacological and the physico-chemical properties of the anticholinergic drugs investigated here ${ }^{6}$.

Zusammenfassung. Mittels Fluoreszenzmessung wurde die durch Acetylcholin aktivierte Indoloxydation verfolgt. Es wurde festgestellt, dass alle im Versuch verwendeten anticholinergischen Substanzen diese Reaktion konzentrationsabhängig abschwächen. Ist kein Aktivator vorhanden, verläuft die Indoloxydation äusserst langsam. Es wird angenommen, dass die anticholinergischen Substanzen die aktivierende Wirkung des Acetylcholins aufheben.

Department of Pharmacology,

E. KunEC-VAJIĆ

Medical Facully, University of Zagreb (Yugoslavia), 24 June 1970.

1 E. KuneC-VAIrĆ and K. Weber, Experientia 23,432 (1967).

2 E. Kunec-Vajic and K. Weber, 5th FEBS meeting (Prague 1968), Abstr. 850.

3 B. Genauf and J. Goldenson, Analyt. Chem. 29, 276 (1957).

* W. Weber and G. Karamanjan, Acta med. iugosi. 2, 64 (1948).

s O. Stern and M. Volmer, Physikal. Z. 20, 183 (1919).

B For generous supplies of the anticholinergic drugs the author is indebted to the firms: Abbott Laboratories, Bristol Laboratories Int., Burroughs Wellcome \& Co., Ciba Ltd., Lakeside Laboratories, Schering Corp. and Wyeth Internat. 